\title{
Knowledge mobilisation crossing boundaries: a multi-perspective framework for agri-food value chains
}

\author{
S. Liu, G. Zhao and H. Chen, University of Plymouth, Plymouth, UK \\ A. Fernandeza, D. Torres ${ }^{a, b}$ and L. Antonellia, (a)LIFIA-CICPBA, Facultad de Informática, \\ UNLP, Argentina; (b) Dto CyT, UNQ, Argentina \\ H. Panetto and M. Lezoche, Université de Lorraine, CNRS, CRAN, Nancy, France
}

\begin{abstract}
Knowledge has long been recognised as a valuable asset to individuals, organisations and economy, subsequently knowledge management (KM) has been a well-established area of research. Existing research has developed various classification schemes for knowledge, and a great number of KM process and lifecycle models have been proposed over the last few decades. In particular, knowledge transfer and sharing has received great attention. However, majority of existing work has focused on knowledge sharing within the same organisation or community where people have a shared sense of identity, values and some common practice, hence knowledge process and learning is within relatively homogeneous groups. There is inadequate research to address the issue of knowledge boundaries and approaches to knowledge mobilisation spanning across knowledge boundaries. The knowledge boundaries can erect significant barriers to knowledge sharing and flowing especially in value chain context where there are a great number of players from different domains, with varied level of knowledge, having different and possibly conflicting interests - participating in knowledge sharing activities. This paper will explore how such knowledge boundaries can be identified and how knowledge gaps among different value chain players can be closed by using appropriate boundary-crossing mechanisms. A multi-perspective knowledge mobilisation framework is proposed. Example applications of the knowledge mobilisation framework in agri-food value chain will be illustrated, based on the most recent developments from an EU collaborative project, RUC-APS (standing for Risk and Uncertain Conditions in Agriculture Production Systems), which is funded by European Commission's Horizon 2020 RISE programme.
\end{abstract}

Keywords: knowledge boundaries, boundary classification, boundary-spanning mechanisms, knowledge sharing and flowing, agricultural value chain

\section{INTRODUCTION}

Knowledge has long been recognised as one of the most valuable assets to individuals, organisations, economy and nations (Drucker, 1988). In the context of business decisionmaking, individuals with more knowledge tend to have more decision power and influence in their group, organisation or community. At the organisational level, Knowledge-based view (KBV) believes that companies exist because they are in the position to transform individual knowledge into collective knowledge and employ the knowledge for business purpose to gain competitive advantages (Castro, Saez, \& Verde, 2011). The concept of "knowledge economy" has emerged more recently to represent the new economy that is driven by knowledge 
intangibles rather than physical capital, natural resources or low-skilled labour (Jashapara, 2011). Because of this great importance of knowledge, a lot of research has been dedicating to the management of knowledge in order for this valuable asset to be explored to its full potential to the benefit of businesses.

Knowledge Management (KM) has been a well-established area which addresses the activities, processes and lifecycles of knowledge creation, holding, sharing and application. Researchers from various disciplines have made significant contribution to the KM from different perspectives, most notably from Information Systems perspective, human resource perspective and business strategic perspective. The Information Systems perspective focuses on addressing technology issues such as using ICT and Artificial Intelligence in developing knowledge bases and knowledge management systems. Human resource perspective emphasises that majority of knowledge in business practice is in fact personal and tacit, which resides in individual's mind and is embedded within practice and experience, subsequently managing knowledge has to address how to manage talents and experts who hold extensive amount of tacit knowledge. Business strategic perspective highlights that any KM initiatives and programmes should be aligned with organisation's business objectives, that is, to answer the question why it is worth investing in KM projects in the first place. The three perspectives together provide a comprehensive approach to KM and this paper is in line with this integrated approach.

However, knowledge management is not a straightforward task because of various barriers existing among the large number of participants. For example, in the context of agrifood value chains there are a great number of stakeholders who have an interest and participate in the food production chain (Chen, Liu, Zhao, et al, 2019). Figure 1 illustrates a closed loop, sustainable agri-food value chain.

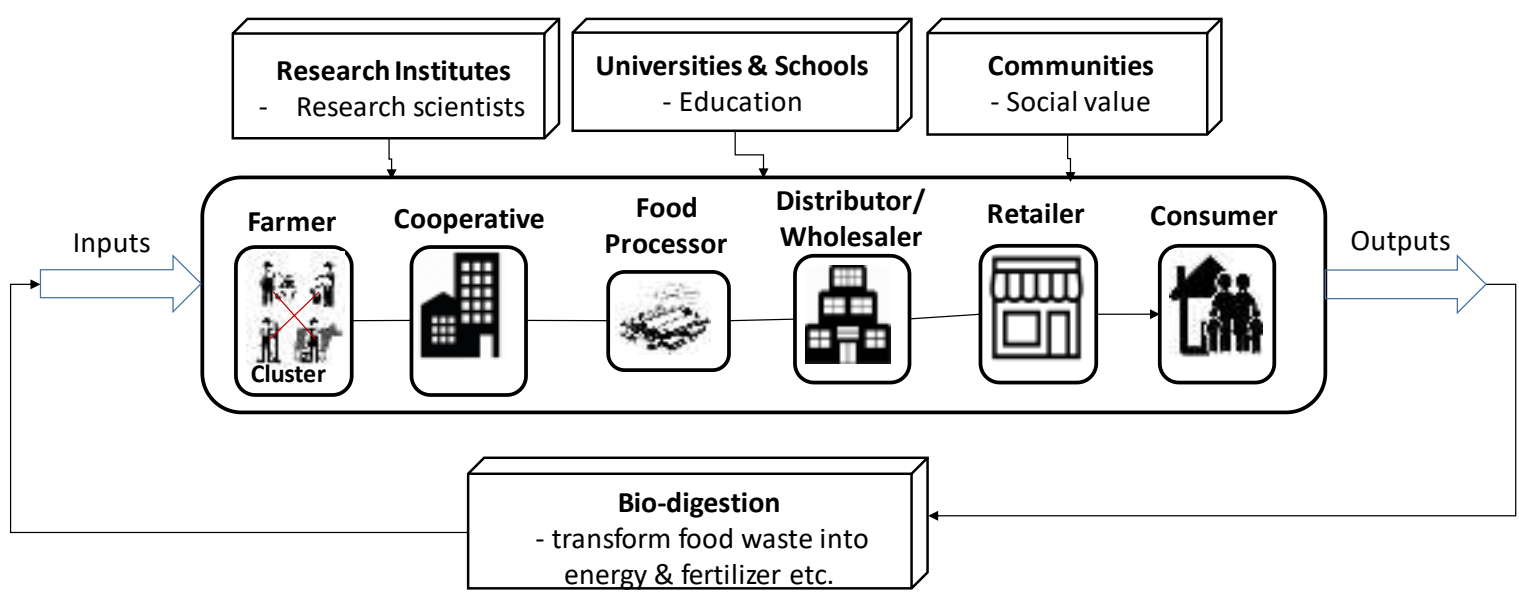

Figure 1 A closed loop, sustainable agri-food value chain

From process and value adding perspective, the food production chain can be seen as a transformation system "from farm to fork", which takes in inputs such as seeds, fertilizers, energy and water, and produce desired outputs. During the transformation process, on the vertical dimension a series of players (from farmers, co-operatives, food processors, distributors/ wholesalers, retailers to consumers) all undertake specific activities and add value. On the horizontal direction, there can be clusters of farmers work collaboratively or share knowledge as needed in order to solve a particular problem, improve efficiency or reduce cost. On the peripheral, there are more players who contribute to the chain activities. 
These include research institutes conducting high quality research which could result in innovations to the sector, for example, by providing new breeding or new methods to control pests. Universities and schools are the key players to provide education to young people and children who can be the leaders for future agri-business and pioneers for changing, for example, green consumption behaviour. These days, there is increasing emphasis on social value that can be supported through agri-business, for example creating community farms where families and friends can enjoy a day on a farm and learn about farming as well. Along with the campaign on sustainability and empowered by technology development, it is now possible to transform food waste, as part of the outputs from the production chain, into energy and fertilisers which can be further feedback and used as inputs to the transformation system. This type of bio-digestion technology allows the agri-food value chain to be a sustainable, closed loop long term.

Despite a great number of KM processes and lifecycle models have been developed over the last few decades within organisations, knowledge sharing and flowing through value chains remain challenging because of the differences and dependencies among the knowledge required for different value chain stage activities, and the uncertainties of the knowledge context influencing the knowledge activities. Subsequently, knowledge boundaries are unavoidable in a value chain. Figure 2 illustrates examples of different knowledge boundaries that potentially exist in an agri-food value chain.

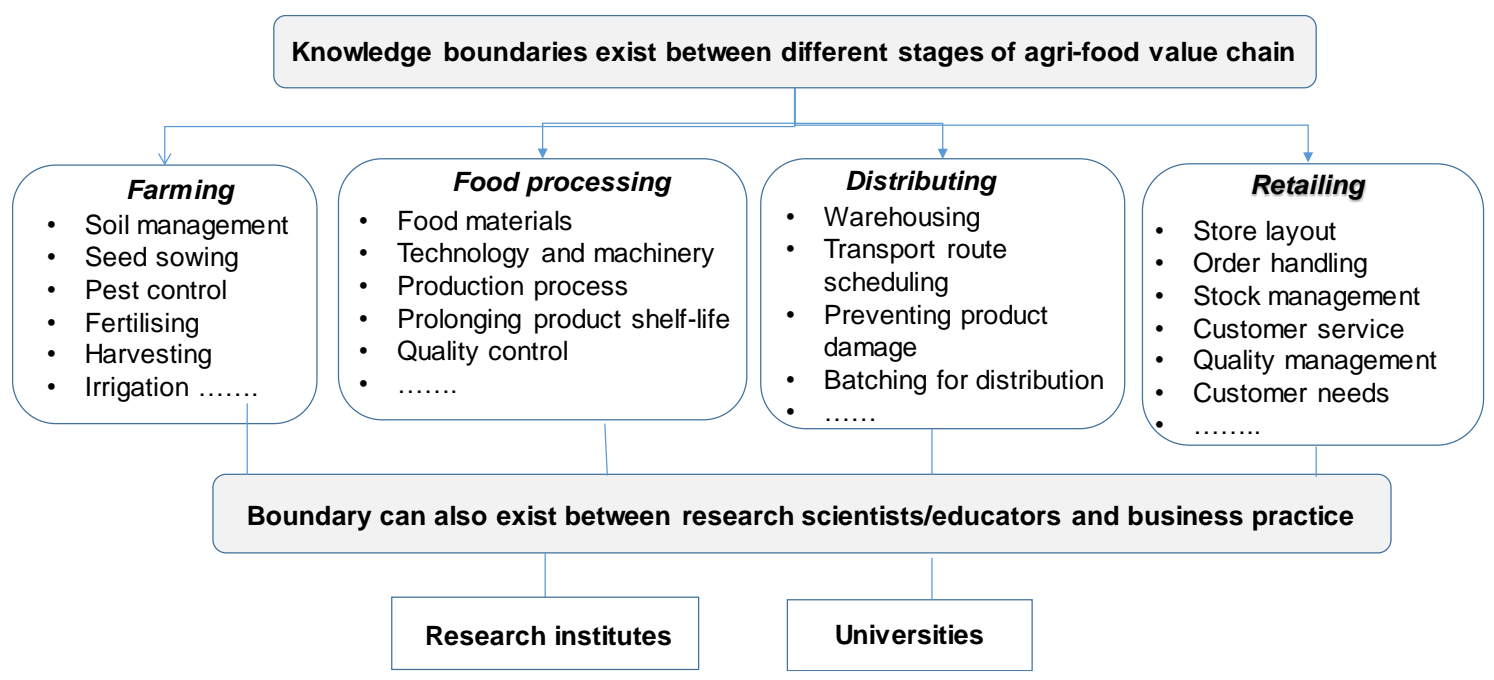

Figure 2 Examples of where knowledge boundaries potentially exist in agri-food value chain

Firstly, knowledge boundaries exist between practitioners at different value chain stages, that is, farmers, food processors, distributors and retailers have different domain knowledge. For example, farmers have knowledge and expertise in soil management, seed sowing, pest control, fertilising, harvesting and irrigation. However, they do not need to have a lot of knowledge in warehousing, transport route scheduling, preventing product damage and batching for distribution, which belong to the distributor's knowledge territory. Secondly, knowledge boundary can also exist between science (such as research scientists at research institutes and universities) and practices (such as farming, food processing, distributing and retailing). Thirdly, knowledge boundary can even exist between people in the same domain but with different amount and level of knowledge, such as between an experienced farmer and a novice farmer. All these knowledge boundaries can create barriers to knowledge sharing and flowing, which would require significant amount of effort from agents with 
structured, planned and systematic approaches to overcoming the barriers (Boshkoska, Liu and Chen, 2018).

Existing research has mainly focused on knowledge activities within an organisation or a community that share common interests or business goals. There is insufficient research addressing knowledge mobilisation crossing boundaries that are potentially erecting barriers for knowledge sharing and flow in value chains. By knowledge mobilisation, we mean by knowledge movement crossing boundaries, which requires more external forces and effort from agent's intervention than usual knowledge sharing activities within the same organisation or community, in order to overcome relevant barriers and move knowledge across boundaries. This paper will aim to address the issues of knowledge boundaries and explore boundary-crossing mechanisms, in order to enable knowledge mobilisation using agri-food value chain as the focal sector of the study.

\section{LITERATURE REVIEW}

This section reviews literature on related work and provides theoretical background for knowledge mobilisation. Firstly, this section discusses literature on distinguishing tacit and explicit knowledge as well as the conversion between tacit and explicit knowledge. Secondly, this section analyses some well-known KM process models.

\section{Tacit and explicit knowledge conversion}

Knowledge is generally classified into two types: tacit knowledge and explicit knowledge. Tacit knowledge refers to knowledge that people possess, for example, intuitions, unarticulated mental models and embodied technical skills. The main characteristics of tacit knowledge is that it is personal, and is difficult, if not possible, to disembody or codify (Nonaka, Umemoto \& Sasaki, 1998; Dalkir, 2017). Tacit knowledge is extremely important to an organisation's R\&D and innovation, hence long-term prosperity and sustainability of business (Roy \& Mitra, 2018). However, tacit knowledge can be easily lost when an employee with expertise leaves an organisation. On the other hand, explicit knowledge is impersonal, context independent and can be easily codified and stored in tangible forms such as books, reports or drawings. Many scholars believe that in business, majority of knowledge is tacit instead of explicit, which presents a great challenge to organisations in terms of $\mathrm{KM}$, that is, how to convert tacit into explicit knowledge in order to be shared across individuals, groups, organisations and communities (Nonaka, 1994; Feghali \& El-Den, 2008).

To enable the conversion between tacit and explicit knowledge, considerable research has been undertaken and one of the most famous research outputs is SECI model (Nonaka \& Takeuchi, 1995). SECI model introduces four processes that can enable conversion between tacit and explicit knowledge. The four processes are socialisation, externalisation, combination and internalisation.

Socialisation is the process that individual tacit knowledge can be converted into common/shared tacit knowledge, in other words, when individuals socialise, interact with each other, they share experience and create common unarticulated beliefs or embodied skills. During socialisation, tacit knowledge stays in tacit form which is rarely captured, noted or written down anywhere, in other words, it remains in the minds of the original participants (Dalkir, 2017), but the process can help to create the invisible bonds of group, organisation or community (Nonaka, Umemoto \& Sasaki, 1998). Externalisation is the process of giving a visible form to tacit knowledge, that is, articulating tacit knowledge into explicit knowledge, subsequently can be represented in tangible forms, saved and stored in repositories such as tools, systems and technologies. The resulted explicit knowledge can then be shared by 
employees in an organisation and may become part of its organisational memory (North \& Kumta, 2018). In this case, the explicit knowledge can be retained even if the people from whom the tacit knowledge resided leave the organisation, the knowledge loss will be less severe. That is why the externalisation process is very important from the management point of view in organisations. Combination is the process of assembling discrete pieces of explicit knowledge into systematic explicit knowledge. Some examples would be a synthesis in the form of a review report, a trend analysis, a brief executive summary or a new database to organise content. In other words, combination happens when concepts are sorted and systematised in a knowledge system (Dalkir, 2017). Generally, it is considered for situations that individual's explicit knowledge is accumulated to form an organisation's knowledge base, however this knowledge combination process does not necessarily expand the organisation's knowledge base (Jashapara, 2011). Finally, internalisation is the process of converting explicit knowledge into tacit operational knowledge such as how-how. Internalisation occurs through the diffusion and embedding of newly acquired behaviour and newly understood or revised mental models. Once new knowledge has been internalised, it is then used by employees, who broaden it, extend it and reframe it within their own existing tacit knowledge bases. They understand, learn and buy into the new knowledge and now do their jobs and tasks differently (Dalkir, 2017). It needs to be emphasised that the above four knowledge conversion/creation processes are not just one-off occurrence, but rather together to form a knowledge spiral for continuous learning and improvement.

\section{KM process and key stages}

There have been hundreds of KM processes being discussed in literature. Heisig (2009) undertook a comprehensive review on the topic and compared $160 \mathrm{KM}$ frameworks. Despite the diversity of KM frameworks and use of terms, there are some common underlying stages for KM processes. We divide a KM process into four key stages, as shown in Figure 3.

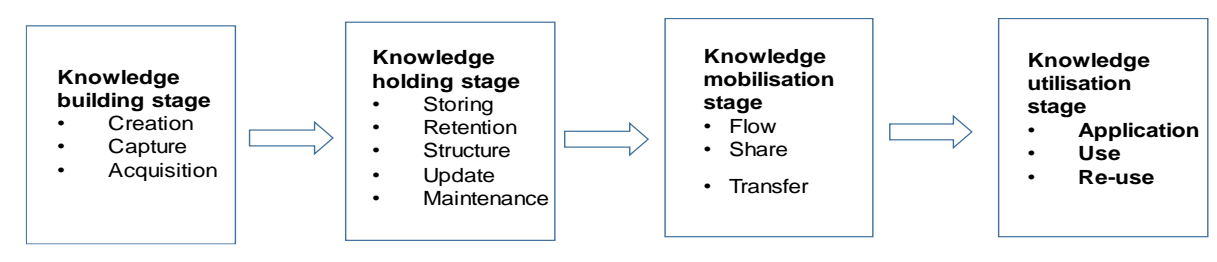

Figure 3 Key stages in a KM process

- Knowledge building stage: this includes knowledge activities happening in the early stage of KM, such as knowledge creation, capture and acquisition (Dalkir, 2017). One key feature of this stage is the increase of knowledge amount such as from zero to existence through creation or capture, and from low volume to higher volume through acquisition.

- Knowledge holding stage: this stage is about keeping knowledge for later use. The inventory of knowledge is a crucial factor to assess the intellectual capital of an organisation. During this stage, the inventory level of total knowledge may not change but knowledge is likely to be sorted, structured or indexed for easy retrieval when needed (Becerra-Fernandez \& Sabherwal, 2015).

- Knowledge mobilisation stage: at this stage, knowledge flows from one place, person, ownership to another through knowledge sharing, transfer or dissemination activities. In this sense, it is a dynamic phase in which people needing knowledge for specific tasks 
can be efficiently matched with counter-parties possessing that knowledge (Venkitachalam \& Bosua, 2014).

- Knowledge utilisation stage: this is where knowledge is used, re-used or applied in practice through decision making, actions and problem-solving activities (Nesheim, Olsen \& Tobiassen, 2011).

It has to be emphasised that these four stages of a KM process are essential and the four stages cannot be separated from each other. Missing any stage of the process can cause disastrous consequences for a KM initiative in practice. In particular, for the knowledge mobilisation to take place, there has to be a transmission process of knowledge (Oyemomi, Liu, Neaga, et al, 2018). Some form of supporting resources are required, such as certain media or carrier where knowledge is embedded, or people in the case of tacit knowledge mobilisation. Knowledge mobilisation can be initiated in two ways. It can be initiated by knowledge owners, who voluntarily donate knowledge to the workplace or community for sharing. In this case, knowledge seekers can collect and gather the knowledge from the knowledge owners. On the other hand, knowledge may be requested by knowledge seekers, and if knowledge contributors are willing to share their knowledge, then the knowledge mobilisation process will also occur (Jashapara, 2011). However, knowledge mobilisation should not be interpreted as a straightforward process which simply passing knowledge from one person or organisation to another. It requires the knowledge seekers or requesters or even knowledge brokers to put significant amount of effort and commitment to absorbing the knowledge and exercise their learning and reflection, in order not just for knowledge seekers to receive knowledge, but also improve on the knowledge they have received and even create new knowledge (Phelps, Heidl \& Wadhwa, 2012).

\section{Research gaps in literature}

In spite of all the efforts in literature to address different types of knowledge, tacit and explicit knowledge conversion, and definition of KM process stages, existing research is mainly focused on knowledge sharing and flow within the same organisation or communities, in which common interests or cultural background is evident. This means that knowledge activities are taking place within homogeneous context. There is little report on knowledge mobilisation crossing knowledge boundaries, such as knowledge sharing and flowing through a value chain. There is a clear need to investigate the research issue of knowledge mobilisation crossing boundaries in agri-food value chain "from farm to fork", and overcoming barriers between science and agri-business practices. The next section proposes a multi-perspective knowledge mobilisation framework to address the issue.

\section{A MULTI-PERSPECTIVE KNOWLEDGE MOBILISATION FRAMEWORK}

This paper proposes an integrated knowledge mobilisation framework, short for 4-4-3 framework, as shown in Figure 4. The 4-4-3 framework represents four boundary-crossing mechanisms from four perspectives that can be used to help cross three types of knowledge boundaries. The key elements of the 4-4-3 framework are:

- Four perspectives: actor perspective, activity perspective, artefact perspective and content perspective.

- Four boundary-crossing mechanisms: boundary objects, boundary spanners, boundary practice and boundary discourse.

- Three boundary types: syntactic boundary, semantic boundary and pragmatic boundary.

The key elements and relationships among them are explained in detail as below. 


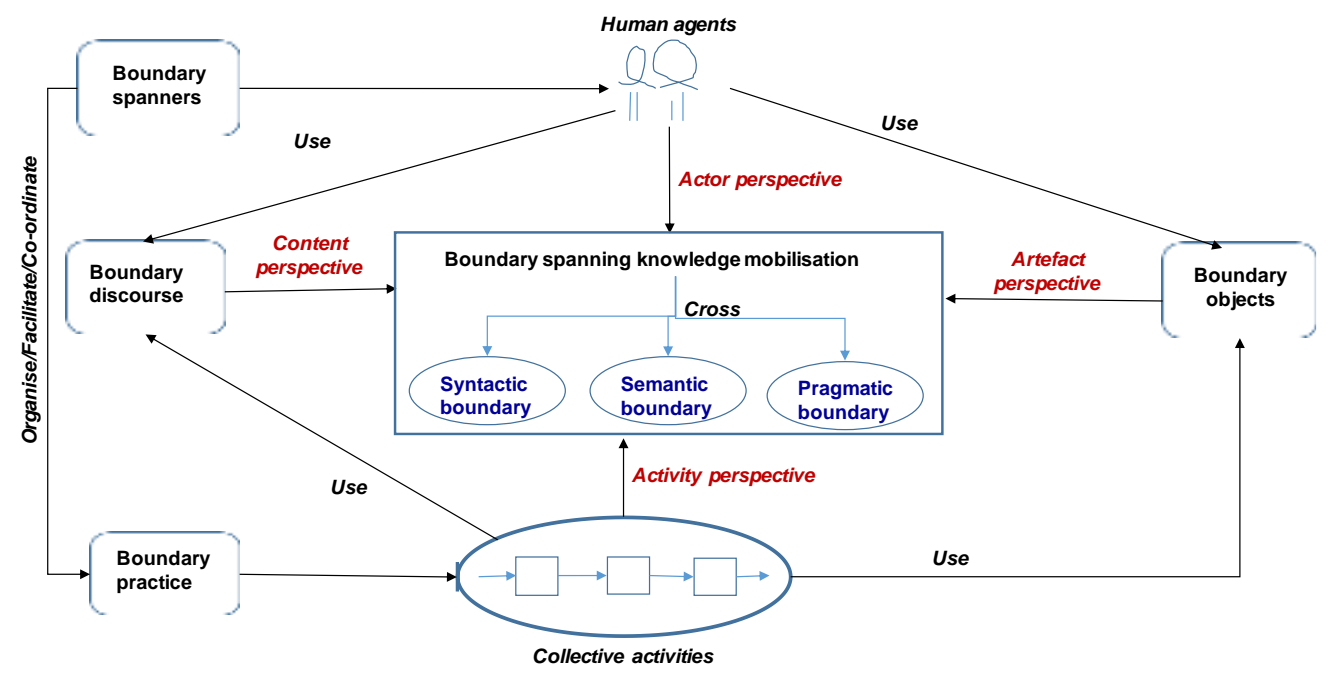

Figure 4 The 4-4-3 formation framework for knowledge mobilisation

\section{The three boundary types}

A knowledge boundary represents the limit or border of an agent's knowledge base in relation to a different domain of knowledge. Knowledge boundaries exist because of many reasons, for example, due to the differences in their knowledge base, the way people work and share knowledge and expertise, and different organisational culture (Boshkoska, Liu \& Chen, 2018). One of the most influential work on knowledge boundaries is probably from Paul Carlile, who developed a topology of knowledge boundaries according to the degree of novelty of the collective tasks being undertaken varying from low to high. He classified knowledge boundaries into three types that have been now widely cited by other scholars and researchers: syntactic boundaries, semantic boundaries and pragmatic boundaries (Carlile, 2002; Carlile, 2004). These three types of knowledge boundaries are sitting in the centre of the 4-4-3 knowledge mobilisation framework because they are the key research issues that need to be addressed.

- Syntactic boundaries: this type of boundary is assumed to be with low level of novelty of the collective tasks being undertaken and the easiest to work across, because in this context people share a common logic, a set of values and worldview (Jashapara, 2011; Hislop, Bosua \& Helms, 2018).

- Semantic boundaries: at this type of knowledge boundary, people do not have a shared logic or shared values. Instead, people may have different understandings and interpretations of the same knowledge. The level of novelty of the collective tasks being undertaken is higher than that at the syntactic boundary (Carlile, 2002; Carlile, 2004).

- Pragmatic boundaries: when novelty level of the collective tasks increases even further, people not only have different interpretations and understandings of knowledge/ issues/ events, they also have different interests, ultimately resulting in conflicts among different actors/ parties (individual, groups/ teams, organisations or communities). Subsequently, pragmatic boundaries are the most complex and difficult to work cross successfully (Filstad, Simeonova \& Visser, 2018). This type of knowledge boundary is also referred to as political boundary.

In essence, at syntactic boundary, there is a lack of common languages, vocabulary or lexicon. At semantic boundary, it lacks common understanding and interpretation. At the pragmatic boundary, there is a lack of common interests. These knowledge boundaries can 
erect great barriers to knowledge sharing and mobilisation, subsequently hinder coordination and problem solving among individuals, groups/ teams, organisations and communities. The pressure from globalisation requires business decision makers to respond and act quickly which has intensified the need to develop strategies and find solutions that can rapidly overcome knowledge boundaries. The next section will discuss boundaryspanning mechanisms to address the issue.

\section{The four boundary crossing mechanisms}

Despite the centrality of knowledge boundaries in business and open innovation, the assumption of permeable boundaries is taken for granted sometimes and yet remains ill understood. This section will explain four specific boundary-spanning mechanisms included in the framework: boundary objects, boundary spanners, boundary practice and boundary discourse. Boundary objects and boundary spanners are relatively well-known mechanisms, while boundary practice and knowledge discourse are quite new concepts and under researched.

\section{Boundary objects}

Boundary objects refer to physical, abstract or mental entities/ artefacts that are common to a number of domains and serve as a focal point in collaboration enabling parties to represent, transform and share knowledge (Carlile, 2002; Carlile, 2004; Hayes \& Fitzgerald, 2009; Hawkins \& Rezazade, 2012). Boundary objects are used to de-contextualise and depersonalise knowledge so that knowledge can be transformed from one domain to another. Boundary objects are flexible enough to allow individuals, groups/ teams, organisations, communities from different domains to attach localised meanings to the object. While there is enough common, shared meaning across domains, it will enable the object to bridge the cognitive gap (Koskinen, 2005). Four types of boundary objects have been distinguished:

- Repositories: supply a common reference point of data, measures or labels across domains or functions that share definitions and values for solving problems, for example, a food gene bank, a food nutrients database and a food chain library.

- Standardised forms and methods: such as standards for food labelling and pro-forma for food quality inspection. They provide a shared format for solving problems across different domains and functional settings. When forms in mutually understood structure and language are used, defining and categorizing differences and potential consequences become more sharable and less problematic across different settings.

- Artefacts or models: they are simple or complex representations that can be observed and used across different domains and functional settings. Examples include food processing flow-charts, supply chain networks, food gene sequencing models and computer simulations.

- Maps of interdependency: They represent dependencies and boundaries that exist between different groups, functions or organisations at a more systemic level, such as ontologies that outlines the dependency between food processing activities, food waste and product shelf-life.

So far, boundary objects have been mainly used in engineering context such as in product design and development, where boundary objects have been used to help bridge the gaps between design, manufacturing and production functions (Carlile, 2002; Carlile, 2004).

\section{Boundary spanners}


Boundary spanners are human agents who can frame and translate knowledge from one domain to another, in an effort to promote knowledge sharing and leaning, further to facilitate co-ordination and problem solving among individuals, groups/ teams, organisations and communities from different domains (Hawkins \& Rezazade, 2012; Zhang et al, 2015). The standing of the human agents and their social relationships in a community, organisation or group/ team are important factors to affect the effectiveness of knowledge mobilisation. The legitimacy of boundary spanners is usually through membership. Based on the membership status of the spanners, different types of boundary spanners have been differentiated:

- Boundary translators: individuals with membership in only one party at the knowledge boundary (Brown \& Duguid, 1998).

- Boundary brokers or boundary crossers: Brown and Duguid (1998) labelled individuals who have memberships in both parties that are involved in the knowledge sharing process as knowledge brokers, while Hayes and Fitzgerald (2009) labelled them as boundary crossers.

- Marginal people: individuals who have membership in multiple parties (Star \& Griesemer, 1989).

It is argued that boundary translators can be tempted to bias knowledge translation in order to favour one community, organisation, or group/ team over another, especially for boundary translators because they only reside in party (Nonaka et al, 2000). For boundary brokers or crossers who have dual membership status, research found that working across organisational and occupational boundaries is still difficult, demanding, and from a career perspective, potentially dangerous (Hayes \& Fitzgerald, 2009). For marginal people, even though they have membership status in multiple communities, organisations, groups/ teams, they may still feel unaccepted in all communities, organisations, groups/ teams as the term alludes. Hence, having membership alone does not necessarily make the knowledge mobilisation crossing boundaries straightforward.

\section{Boundary practice}

Boundary practice is a boundary spanning mechanism that overcomes knowledge boundaries by engaging agents from different knowledge domains in collective activities (Hawkins \& Rezazade, 2012). The focal unit of analysis of this mechanism is practice. Boundary practice have the capability of engaging knowers from different domains in a shared site of knowing. Engaging in collective practice at the boundary of different knowledge areas creates a situation that facilitates the development of new knowledge through, for example, socialisation process as defined in SECI model. Boundary practice is most effective in addressing knowledge boundaries involving tacit knowledge through learning by doing (i.e. internalisation in SECI terms).

Boundary practice is different from routine practice or the boundary work that are well-established operations, because boundary practice has significant novelties for experts from different domains. Boundary practice involves an overlap of activities from different agents, but the practice itself is not specialised to a particular individual, group/ team, organisation or community, because the particular boundary practice emerges out of context and participating agents' collective activities (Hawkins \& Rezazade, 2012). Boundary practice is also different from specialised practice, because boundary practice should be un-assignable or un-separable into sub-tasks that can be delegated to experts in each specialised domain. The collective activities should be performed together within a flexible space between the 
domains of expertise (Nicolini, 2011). Boundary practice as a boundary spanning mechanism is a relatively new concept, and research in this area is still in its early stage.

A good example of boundary practice in the agricultural context is "care farming" projects or called "social farming" projects. Care farming is the therapeutic use of farming practices, by

- Providing health, social or specialist educational care services for individuals from one or a range of vulnerable groups;

- Providing a programme of farming-related activities for individuals with a defined need, including animal husbandry (livestock, small animals, poultry), crop and vegetable production, woodland management etc.;

- Providing services by a range of referral agencies such as social services, health care trusts, community mental health teams, education authorities, probation services, national careers service etc. Of course, care farming can utilise the whole or part of a farm, be they commercial agricultural units, smallholdings or community farms.

All the people and groups, whether they are farmers with specialised expertise or individuals who are there to provide social services or to receive education and therapy, engage in the "care farming" practice, work and learn together collectively. During the process, knowledge is mobilised crossing all types of knowledge boundaries. The UK government has seen the great importance of this type of shared practice in education and officially launched a $£ 1.4$ million project on 31st January 2019 led by "Social Farms and Gardens", which is an exciting opportunity to build the capacity and scale of the care farming sector. The project aims to expand and transform care farming services across all nine English regions and ultimately create more opportunities for both children and adults with a defined need to benefit from attending care farms, for health, social or specialist educational care services (https://www.carefarminguk.org/home).

\section{Boundary discourse}

Boundary discourse refers to the content of knowledge that shapes the dialogue among the experts from distinct domains (Hawkins \& Rezazade, 2012). In other words, the primary attention is paid to what is communicated that will build knowledge to ultimately allow the parties closing the cognitive gap. In order to effectively engage experts from different domains in a dialogue and acquire the needed knowledge, the content such as ideas and issues of a dialogue should have certain level of conceptual overlap (in-between-ness) with the cognitive schemas of involved experts, thus properly distinct from dominant discourse within each domain.

The comparison of the four boundary-crossing mechanisms can be summarized from a number of aspects:

- Unit of analysis: human agents are the unit of analysis for boundary spanners, artefacts for boundary objects, practice (i.e. collective activities) for boundary practice, and content of knowledge for boundary discourse.

- Important attributes of the units: important attributes of boundary objects are shared meaning, materiality, physicality, abstraction and mental presence. Key attributes of boundary spanners include membership status, personalities, skills, cognitive capabilities, and various types of relations. Engaging and collective activities are crucial for boundary practice. For boundary discourse, it needs ideas, domains of knowledge and cognitive proximity. 
- Type of knowledge shared at the boundary: among the four boundary spanning mechanisms, boundary practice is most effective with tacit knowledge, while the other three mechanisms (i.e. boundary spanners, boundary objects and boundary discourse) are most effective mainly with explicit knowledge.

- Knowledge spanning functions: main knowledge function of boundary objects is transforming knowledge, by objectifying concepts that otherwise might have been difficult to notice. In comparison, boundary spanners translate and frame/ reformulate knowledge from one domain to another. Differently, boundary practice fills knowledge gaps by creating new knowledge between distinct domains of knowing through joint activities. Finally, boundary discourse enhances the opportunities for knowledge building by sensitizing involved parties about ideas and themes, selecting and situating the dialogue on specific themes, and articulating and clarifying the knowledge of one side to be transferred to the other side.

\section{The four knowledge mobilisation perspectives}

In a knowledge spanning process, several boundary spanning mechanisms are usually integrated and explored by organisation experts simultaneously or over time, in other words, a combination of the boundary spanning mechanisms is often used to support each other in knowledge sharing and learning process at boundaries. Research has revealed that individual mechanism can benefit from the compounding effect of being linked together with other mechanisms. In fact, it can be considered that the four boundary spanning mechanisms provide four complementary perspectives of a boundary spanning knowledge process. They are the actor perspective provided by boundary spanners, the artefact perspective provided by boundary objects, the activity perspective provided by boundary practice, and the content perspective provided by boundary discourse. Boundary spanners represent human agents, who can organise, facilitate and co-ordinate the collective activities inherent within boundary practice. Both boundary spanners and boundary practice may need to use appropriate boundary objects in facilitating knowledge sharing and learning activities. In any boundary spanning knowledge process, the content of knowledge provided through knowledge discourse is of paramount importance to both boundary spanners and boundary practice in terms of what is actually communicated or what is actually done. That is why when a number of the boundary spanning mechanisms are used together in harmony, the boundary spanning knowledge process will be likely more effective and complete.

\section{EXAMPLE APPLICATIONS IN AGRI-FOOD CONTEXT}

This section presents an example application of knowledge mobilisation framework in the context of agri-food value chains, through two stages. Stage one involves the development of AgroKnolwedge ontology which defines knowledge classes and specifies relationships between knowledge classes, then Stage two presents a knowledge formalisation approach that can transform tacit knowledge into explicit knowledge for ontology implementation. The final purpose is to build a repository for best practice that can be used for various stakeholders in the agri-food value chain to mobilise knowledge crossing knowledge domains.

\section{Argoknowledge onlotogy}

The main goal of Agroknowledge is to build a collaborative and semantic repository of good practices in horticulture and to apply gamification strategies to improve collaborative knowledge building in order to achieve sustainable participation. Agroknowledge is focused 
on horticultural belt of La Plata, Argentina. Figure 5 describes the ontology defined to represent the main classes and the relationships between the classes for the development of the Agroknowledge repository. For each class, a list of attributes is specified. The nature of the relationships is labelled on the respective linking lines. For example, good practice uses tools, and tools require appropriate resources, uses supply and produces waste. In the meantime, good practice can be applied for certification and solves problems. The definitions of each of the classes in the ontology are detailed in Table 1 for clarity.

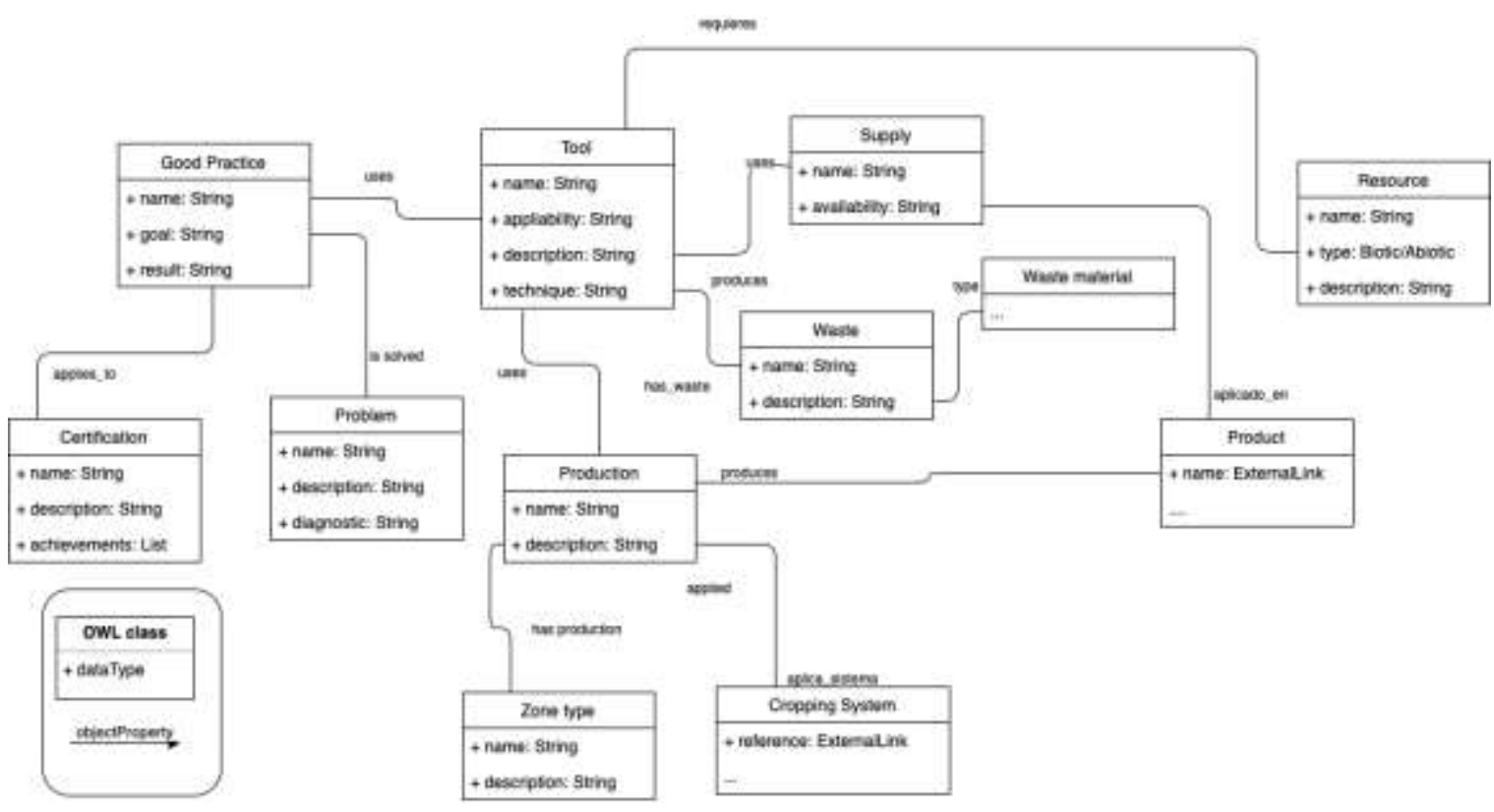

Figure 5 The ontology for Agroknowledge repository

Table 1 Definitions of the classes

\begin{tabular}{|l|l|}
\hline Class & Description \\
\hline Good Practice & $\begin{array}{l}\text { A principle, regulation or technique to production addressing human } \\
\text { health care, environment protection and improvement or worker } \\
\text { conditions. (FAO) }\end{array}$ \\
\hline Tool & A strategy to accomplish the good practice \\
\hline Supply & Elements uses in a tool \\
\hline Waste & Unwanted materials produced by the performance of a tools \\
\hline Waste Material & Kind of waste such as organic or inorganic \\
\hline Resource & Natural elements involved (Water, Sol, Air) \\
\hline Product & Wanted element produced in a production (tomato, spinach, etc) \\
\hline Production & Type of production. How is organized the production activity \\
\hline Zone Type & Characterize the geographic and spatial area \\
\hline $\begin{array}{l}\text { Cropping } \\
\text { System }\end{array}$ & Refers to the crops and particular techniques in the agricultural field \\
\hline Problem & The problem a farmer could have in the horticultural labour. \\
\hline Certification & $\begin{array}{l}\text { External set of rules to attesting a certain level of horticultural } \\
\text { achievement }\end{array}$ \\
\hline
\end{tabular}




\section{Knowledge formalisation for ontology implementation}

The challenge of transforming tacit knowledge possessed by a model into explicit knowledge can be approached by the formalisation of the knowledge (Wajnberg et al, 2017). In the very moment the structure is identified the treatment can be automatized. This approach has three pillars: the concepts, the relationships and the properties. The formal constraints between those elements create the knowledge in the form we are used to knowing it (Lezoche et al, 2012).

A general concept can be represented by a set of objects or by a set of properties. The first solution is a simple enumeration and the second is the relation between the concept and all the properties owned by the concept itself. A mathematical approach, called formal concept analysis (FCA), consists in organizing the concepts into a hierarchy from a formal context. The formal context is a set of objects with the properties of each object. This hierarchy will be represented under the shape of a lattice (Wille, 1982).

The FCA theory identifies conceptual structures among data sets. These structures are represented as conceptual lattices, allowing the analysis of complex structures and the discovery of dependencies within the data. The FCA is a conceptual clustering technique with mathematical foundations. It is based on the understanding that a concept is constituted by two parts: its extension which consists of all objects belonging to the concept, and its intension which comprises all attributes shared by those objects. This understanding allows to derive all concepts from a given context (data table) and to introduce a subsumption hierarchy. The FCA approach allows to make explicit knowledge from a single-context system, and in a certain way, can be seen as a clustering method, where each concept is a cluster. And from each concept, knowledge can be extracted.

\section{Formal Concept Analysis}

The FCA approach has been introduced gradually by a number of scholars (Wille, 1982; Carpineto et al., 2004; Ganter et al., 2012). It is a method that has the goal of organizing information from a context in a way that knowledge can be easily extracted in the form of association rules on a dataset. A simple introduction to FCA starts from a triple:

- A set of objects 0 .

- A set of attributes A

- A binary relation $\mathrm{I} \subseteq 0 \times \mathrm{A}$ called incidence that expresses which objects have which attributes.

The set of objects $O$ and a set of attributes $A$ can be easily represented by a cross-table that gives each object $o \in O$ the set of attributes $\mathrm{A} \subset A$ that $o$ has. Such a cross-table is called a formal context.

A cluster in formal concept analysis is defined by the name formal concept. A formal concept is a pair $(X, Y) \subset O \times A$ where every element $o \in X$ carries every single attribute $a$ present in $Y$ and such that there are no other objects of $O$ than these of $X$ that carries simultaneously every attribute of $Y$.

The FCA method has as a goal the definition, from the context $K$ set, of all the concepts $C_{K}$. It, also, gives to this set of concepts an order relation: a concept $C_{2}$ is greater than a concept $C_{1}$, if and only if, the set of objects of $C_{1}$ is a subset of the set of objects of $C_{2}$.

$$
\forall c_{1}=\left(X_{1}, Y_{1}\right) \in C_{K}, \forall c_{2}=\left(X_{2}, Y_{2}\right) \in C_{K}, c_{1} \leq c_{2} \Leftrightarrow X_{1} \subset X_{2}
$$

Provided with that order relation, $\left(C_{K}, \leq\right)$ defines a Partially Ordered Set (POSET), and in particular a complete lattice. Numerous algorithms have been developed in the literature to conceive such a lattice from the formal context (Kuznetsov, 2002; Stumme, 2009). 
The lattice structure allows an easy reading to extract knowledge from the clusters: any concept in the lattice gives an information of the shape "all the objects in those formal concepts share the attributes in the formal concept and they are the only one". Also, if we take any inferior concept, it will give a more specific information. And of course, a superior concept will give a more general observation.

\section{Knowledge formal structure (Ontology) from FCA}

An ontology encompasses a representation, formal naming, and definition of the categories, properties, and relations between the concepts, data, and entities that substantiate one, many, or all domains. In 1993, Gruber originally defined the notion of an ontology as an "explicit specification of a conceptualization" (Gruber, 1993). In 1997, Borst defined an ontology as a "formal specification of a shared conceptualization" in (Borst, 1997). This definition additionally required that the conceptualization should express a shared view between several parties, a consensus rather than an individual view.

Generally, the ontology design is started with designing the hierarchy of relevant concepts. The is-a relation, a taxonomical relation, between concepts, is perceived as the base of any ontology (Liao et al, 2016). This view is mainly given by the procedure of designing object oriented based systems. A typical design approach for modeling of the object-oriented systems is the Universal Modeling Language (UML). While object-oriented systems are not primarily intended for knowledge representation, the approaches are similar to the framebased systems. In these systems, the modeling activity typically starts with designing the hierarchy of classes. The following action is adding the attributes or the properties to the existing hierarchy of classes. These attributes or properties are then inherited along the subsumption (is-a) relation. This procedure leads to, at least, two problems:

- The tendency to create hierarchies of objects with no clear distinctions - to model the domain, there is the introduction of many objects organized in the taxonomical ordering, but that have no other differentiating attributes;

- It is not easy to change the classes and their attributes once they are defined;

To avoid these problems another method for constructing ontologies can be proposed. The main characteristics of this method are that the concepts are described by the properties. Those properties determine the hierarchy of concepts and when the properties of different concepts are the same, then the concepts are the same as well.

The procedure of designing an ontology supported by a tool that uses FCA is focused on adding the concepts and properties from the formal context (Eslami et al, 2019). It uses the lattice of the concepts with their properties to visualize the ontology. Based on the visualization, a designer can edit the ontology if two concepts fall into one place when being visualized by using FCA, they should be either merged to one, or a distinction should be added (a different ownership of properties). Another important point FCA method focuses on is that it can generate concepts that are formed by properties and are super-concepts of the highlighted concepts. Those super-concepts are not explicitly mentioned in the concept table so this does mean that this concept can be created (ontology designer can just add a concept name upon the suggestion, the properties of the new concept are obvious from the generated lattice).

\section{DISCUSSION AND CONCLUSIONS}

In the agri-food value chain context, new knowledge is often created and held at each stage of the value chain separately during everyday practice. In order for effective application of valuable knowledge and improve the business performance of the whole value chain, 
knowledge has to be mobilised crossing knowledge boundaries, be they organisational, geographical or cultural boundaries. This paper proposes an integrated approach to knowledge mobilisation, by systematically exploring boundary-crossing mechanisms from four different perspectives to target three types of knowledge boundaries.

Main contributions of the paper include a number of aspects. Firstly, the work identifies the positions where knowledge boundaries potentially exist in an agri-food value chain. In particular, boundary can exist between different stages of the value chain representing different knowledge domains, between science (such as research undertaken by universities and research institutes) and agriculture practice (Hernandez et al, 2017), and between different levels of knowledge even within the same knowledge domain. Secondly, the paper links three types of knowledge boundaries (syntactic, semantic and pragmatic), four boundary crossing mechanisms (i.e. boundary objects, boundary spanners, boundary practice and boundary discourse) and four perspectives (i.e. actor perspective, artefact perspective, activity perspective and content perspective) to form a holistic view of knowledge mobilisation. Thirdly, the paper presents an example of agriculture good practice repository to illustrate the use of the knowledge mobilisation framework. The good practice ontology has been developed and a knowledge formalisation approach is explained in detail for the ontology implementation, so that tacit knowledge in agricultural good practice can be formally extracted and put in a repository for knowledge sharing and learning crossing boundaries. Future work includes testing the AgroKnolwedge repository with more stakeholders from different knowledge domains and from more geographically dispersed areas, so that the effect of social and cultural background on knowledge mobilisation can be observed.

\section{REFERENCES}

Becerra-Fernandez, I. \& Sabherwal, R., 2015. Knowledge Management: Systems and Processes. $2^{\text {nd }}$ edition. Routledge, Taylor \& Francis Group. Oxon, USA, p. 18.

Borst., W., 1997. Construction of Engineering Ontologies. PhD thesis, Institute for Telematica and Information Technology, University of Twente, Enschede, The Netherlands.

Boshkoska, B.M., Liu, S. \& Chen, H., 2018. Towards a knowledge management framework for crossing knowledge boundaries in agricultural value chain. J. of Decision systems 27(s1): 88-97.

Brown, J.S. \& Duguid, P., 1998. Organising knowledge. California Manag. Rev. 40(3): 90-111.

Carlile, P., 2002. A pragmatic view of knowledge and boundaries: boundary objects in new product development. Organ. Sci. 14(4): 442-455.

Carlile, P., 2004. Transferring, translating and transforming: an integrative framework for managing knowledge across boundaries. Organ. Sci. 15(5): 555-568.

Castro, G. M., Saez, P. L. \& Verde, M. D., 2011. Towards a knowledge-based view of firm innovation. J. of Knowledge Manag. 15(6): 871-874.

Chen, H., Liu, S., Zhao, G., Guyon, C., Boshkoska, B.M. and Oderanti, F.O., 2019. Identifying knowledge brokers, artefacts and channels for waste reduction in agri-food supply chains. International Journal of Sustainable Agriculture Management and Informatics, 4(3): 273-289.

Drucker, P., 1998. The coming of the new organisation. Harv. Bus. Rev 66(1): 45-53.

Dalkir, K., 2017. Knowledge Management in Theory and Practice, 3rd edition. Cambridge, MA: MIT Press.

Eslami, Y., Dassisti, M., Lezoche, M., Panetto, H. 2019. A survey on sustainability in manufacturing organisations: dimensions and future insights. International Journal of Production Research, Taylor \& Francis, 2019, 55th Anniversary Special Issue, 57, 〈10.1080/00207543.2018.1544723 $\rangle$.

Feghali, T. \& El-Den, J., 2008. Knowledge transformation among virtually co-opertaing group members. J. of Knowledge Manag. 12(1): 92-105. 
Filstad, C., Simeonova, B. \& Visser, M., 2018. Crossing power and knowledge boundaries in learning and knowledge sharing: The role of ESM. The Learning Organization 25(3): 159-168.

Gruber., T. R., 1993. A Translation Approach to Portable Ontologies. Knowledge Acquisition, 5(2):199-220.

Heisig, P., 2009. Harmonisation of knowledge management - comparing $160 \mathrm{KM}$ frameworks around the globe. J. of Knowledge Manag. 13(4): 4-31.

Hawkins, M.A. \& Rezazade, M.H., 2012. Knowledge boundary spanning process: synthesizing four spanning mechanisms. Manag. Decisions 50(10): 1800-1815.

Hayes, K. \& Fitzgerald, J., 2009. Managing occupational boundaries to improve innovation outcomes in industryresearch organisations. J. of Manag. and Organ. 15(4): 423-437.

Hernandez, J., Kacprzyk J., Panetto, H., Fernandez, A., Liu S., Ortiz, A., De-Angelis, M., 2017. Challenges and Solutions for Enhancing Agriculture Value Chain Decision-Making. A Short Review. 18th Working Conference on Virtual Enterprises (PROVE), Vicenza, Italy. Springer International Publishing, IFIP Advances in Information and Communication Technology, AICT-506, pp.761-774, 2017, Collaboration in a 〈10.1007/978-3-319-65151-4_68〉

Hislop, D., Bosua, R. \& Helms, R., 2018. Knowledge Management in Organisations: A Critical Introduction. 4th edition. Oxford University Press.

Jashapara, A., 2011. Knowledge Management: An Integrated Approach. 2nd edition. Pearson Education Limited. Harlow, England.

Koskinen, K.U., 2005. Metaphoric boundary objects as co-ordinating mechanisms in the knowledge sharing of innovation processes. Eur. J. of Innovation Manag. 8(3): 323.

Lezoche, M., Aubry, A., Panetto, H., 2012. Formal Fact-Oriented model transformations for Cooperative Information Systems semantic conceptualisation. Enterprise Information Systems. Lecture Notes in Business Information Processing, 2012, LNBIP 102, pp.117-131. 〈10.1007/978-3-642-29958-2_8〉.

Liao, Y., Lezoche, M., Panetto, H., Boudjlida, N., 2016. Semantic annotations for semantic interoperability in a product lifecycle management context. International Journal of Production Research, 54 (18): 5534-5553.

Nesheim, T., Olsen, K. M. \& Tobiassen, A. E., 2011. Knowledge communities in matrix-like organisations: managing knowledge towards application. J. of Knowledge Manag. 15(5): 836-850.

Nonaka, I., 1994. A dynamic theory of organisational knowledge creation. Organ. Sci. 5(1): 14-37.

Nonaka, I. and Takeuchi, H., 1995. The Knowledge Creating Company. New York: Oxford University Press.

Nonaka, I., Umemoto, K. \& Sasaki, K., 1998. Three tales of knowledge-creating companies. In Knowing In Firms: Understanding, Managing and Measuring Knowledge (edited by von Krogh, G., Roos, J. and Kleine, D.), pp 240-252. Sage Publications, London.

North, K. \& Kumta, G., 2018. Knowledge Management - Value Creation Through Organisational Learning, 2nd edition. Springer, Cham, Switzerland. p. 36.

Oyemomi, O., Liu, S., Neaga, I., Chen, H. \& Nakpodia, F., 2018. How cultural impact on knowledge sharing contributes to organisational performance: using the fsQCA approach. J. of Bus. Research.

Phelps, C., Heidl, R. \& Wadhwa, A., 2012. Knowledge, networks and knowledge networks: a review and research agenda. J. of Manag. 38(4): 1115-1166.

Roy, S. \& Mitra, J., 2018. Tacit and explicit knowledge and assessment of quality performance of public R\&D in emerging economies: an Indian perspective. J. of Organ. Change Manag. 31(1): 188-214.

Venkitachalam, K. \& Bosua, B., 2014. Roles enabling the mobilisation of organisational knowledge. J. of Knowledge Manag. 18(2): 396-410.

Wajnberg, M., Lezoche, M., Massé, B., A., Valtchev, P., Panetto, H., 2017. Complex system tacit knowledge extraction trough a formal method. INSIGHT - International Council on Systems Engineering (INCOSE), 20 (4): 23-26.

Zhang, C., Wu, F. \& Henke, J.W., 2015. Leveraging boundary spanning capabilities to encourage supplier investment: a comparative study. Ind. Marketing and Manag. 49(8): 84-94. 